\title{
Cambios ambientales y geoarqueología en medios áridos/semiáridos: propuesta metodológica
}

\author{
María Marta Sampietro Vattuone, José Luis Peña Monné
}

\begin{abstract}
María Marta Sampietro Vattuone
sampietro@tucbbs.com.ar

Laboratorio de Geoarqueología, Universidad

Nacional de Tucumán, España 2903 - 4000

San Miguel de Tucumán, Argentina.

José Luis Peña Monné

Departamento de Geografía y Ordenación del

Territorio, Universidad de Zaragoza, Pedro

Cerbuna 12, 50009 Zaragoza, España.
\end{abstract}

BOL. SOC. GEOL. MEX. 2019

VOL. 71 NO. 2

P. $565-584$

http://dx.doi.org/10.18268/BSGM2019v7 ln2a19

\section{RESUMEN}

En medios áridos y semiáridos, las respuestas geomorfológicas ante los cambios ambientales holocenos han dejado claros testimonios en los registros sedimentarios, que en muchos casos involucran en su evolución elementos arqueológicos. Estos registros pueden ser analizados desde un punto de vista geoarqueológico para la reconstrucción de contextos de yacimientos y de la evolución post-deposicional que haya modificado sus rasgos originales. En este trabajo se analizan los factores desencadenantes de los cambios ambientales y los procesos geomorfológicos en laderas, terrazas y conos aluviales y en acumulaciones eólicas, describiéndose casos de aplicación geoarqueológica en Argentina y España. Finalmente, se presenta una propuesta metodológica basada en la realización de mapas geomorfológicos de áreas de sitios arqueológicos, la realización de perfiles transversales, longitudinales y estratigráficos de las unidades geomorfológicas analizadas y la elaboración de modelos evolutivos para la reconstrucción paleoambiental, en los que es esencial la correlación regional y global de los resultados.

Palabras clave: modelos geoarqueológicos, reconstrucción paleoambiental, terrazas fluviales, abanicos aluviales, laderas, dunas.

\section{ABSTRACT}

In the drylands, the geomorphological responses facing Holocene enoironmental changes left clear features on the sedimentary records. In several cases, these records involve archaeological features that could be analyzed from a geoarchaeological perspective in order to reconstruct the site context and the post-depositional evolutionary processes that could alter their original features. This paper analyzes the factors that trigger the environmental changes and geomorphological processes in slopes, fluvial terraces, alluvial fans and aeolized areas with study cases from Argentina and Spain. In addition, a methodological proposal is presented for which main steps are based on the preparation of geomorphological maps of archaeological areas, the description of transversal, stratigraph$i c$, and longitudinal profiles, and the construction of evolutionary models for paleoenvironmental reconstruction, on which it is essential for regional and global correlation of the information.

Keyzerds: Geoarchaeological model, paleoenvironmental reconstruction, fluvial terraces, alluvial fans, slopes, dunes. 


\section{Introducción}

Los cambios ambientales, producidos por variaciones de las condiciones naturales, inducidos y/o potenciados por actividades humanas, generan respuestas predecibles en el medio físico cuya interpretación es de gran importancia para comprender las características actuales de los lugares de interés arqueológico y los procesos evolutivos involucrados en la generación de los mismos. Los medios áridos y semiáridos son especialmente sensibles a pequeñas modificaciones en cualquiera de las unidades de paisaje que se consideren (Burillo y Peña Monné, 1984). Esto se debe a que no sólo se ven afectados por tendencias a largo plazo que pueden ser de décadas, centurias o milenios, sino que tienen gran influencia eventos aislados o de corto plazo, que pueden tener un sentido diferente a la tendencia normal y, sin embargo, convertirse en puntos de inflexión capaces de llevar al sistema a cruzar umbrales de equilibrio geomorfológico.

A escala temporal geológica, un sitio arqueológico es un testigo sedimentario de una o varias fases de ocupación humana que han quedado involucradas en el proceso evolutivo regional durante un tiempo, y que incluso tras su pérdida de uso continúa evolucionando geomorfológicamente como un elemento más del paisaje (Peña Monné, 2018). Su mejor o peor conservación depende, en primer lugar, de las características del propio contexto previo a su ocupación, posteriomente del sistema de asentamiento y, finalmente, del conjunto de procesos de transformación (positivos o negativos) dentro de un sistema evolutivo geomorfológico concreto, que ha podido estar sujeto a cambios de diferente signo hasta llegar a la actualidad (Schiffer, 1990). Por ello, es de vital importancia asumir con una perspectiva geoarqueológica cualquier análisis de un sitio arqueológico, teniendo en cuenta su inmersión en un modelo en el que se crean interacciones entre medio natural y hombre (Sampietro-Vattuone y Peña-Monné, 2014).

Los estudios geoarqueológicos basados en la reconstrucción paleoambiental partiendo del análisis de la dinámica geomorfológica comenzaron en el ámbito mediterráneo (Vita-Finzi, 1969; Brückner, 1998; Butzer, 2005, Bintliff, 2005; entre otros). Es este un espacio geográfico semiárido con alta fragilidad ambiental, en el que la sucesión de desarrollos culturales de tecnología de complejidad creciente y la consiguiente sobreexplotación del territorio, generó cambios notables en la actividad geomorfológica. Sus registros sedimentarios permiten reconstruir cambios ambientales naturales y de influencia antrópica de los últimos cinco mil años (Peña Monné et al., 2004; Peña-Monné y Sampietro-Vattuone, 2014). Similares respuestas en medios áridos y semiáridos de América del Norte (Waters, 2000; Huckleberry y Duff, 2008) y del Sur (May et al., 2015) permiten identificar efectos geoarqueológicos análogos, a los que hay que aplicar una metodología basada en modelos evolutivos complejos para extraer la información necesaria para su reconstrucción paleoambiental y conocer el papel que ha jugado la ocupación humana del territorio (Sampietro-Vattuone y Peña-Monné, 2016).

Aunque se han realizado algunas aproximaciones metodológicas previas (Burillo y Peña Monné, 1984; Peña Monné et al., 2005; PeñaMonné y Sampietro-Vattuone, 2014; SampietroVattuone et al., 2014) enfocadas hacia cuestiones específicas como el análisis geoarqueológico de fosos defensivos, construcción de modelos geoarqueológicos, reconstrucción de prácticas agrarias, etc., ninguna aborda de manera integral y comprehensiva la temática de la presente propuesta. El objetivo de este trabajo es proponer una metodología de análisis para la interpretación de los procesos complejos de cambio en diversos ambientes geomorfológicos de medios áridos y semiáridos subtropicales, involucrando agentes naturales con otros humanos de economía agropastoril preindustrial. Se considerarán las diversas respuestas implicadas en los procesos evolutivos en cada caso y los indicadores a tener en cuenta para su identificación. La correcta interpretación de los diversos rasgos implicados en la formación de los contextos disponibles lleva a la reconstrucción de procesos evolutivos de largo 
CAMBIOS CLIMÁTICOS DURACIÓN AMPLITUD DE EFECTOS

\begin{tabular}{|c|c|c|}
\hline $\begin{array}{c}\text { Fases glaciares e } \\
\text { interglaciares del Pleistoceno }\end{array}$ & Larga & Global \\
\hline $\begin{array}{c}\text { Fluctuaciones climáticas } \\
\text { del Holoceno }\end{array}$ & Media & Regional \\
\hline $\begin{array}{c}\text { Eventos climáticos excepcionales } \\
\text { (inundaciones, sequías, etc) }\end{array}$ & Corta & Local \\
\hline
\end{tabular}

Figura 1 Relación entre cambios climáticos y efectos geomorfológicos considerando su duración y la amplitud espacial de los efectos (basado en Burillo y Peña Monné, 1984).

plazo además una contextualización adecuada de los materiales arqueológicos en sus múltiples dimensiones. Se abordarán particularmente las respuestas producidas en ambientes de laderas, sistemas aluviales (incluyendo abanicos y terrazas) y zonas con actividad eólica, dada su alta ubicuidad en los medios estudiados. Como esta metodología ha sido utilizada tanto en la reconstrucción paleoambiental de sitios arqueológicos del Nordeste de España como del Noroeste Argentino, se citarán principalmente ejemplos de aplicación de dichos espacios.

\section{Factores que intervienen en el desencadenamiento de cambios ambientales}

Un territorio determinado posee una identidad inicial propia relacionada con su dinámica geomorfológica que responde a una serie de factores geológicos, climáticos y condiciones topográficas, pero además hay otros factores que son variables en el tiempo que le otorgan su capacidad evolutiva. En los sistemas geomorfológicos los principales factores desencadenantes de cambios son: el clima, la tectónica (afectando al nivel de base), y el hombre (Schumm, 1979; Günster y Skowronek, 2001; Harvey et al., 2005; Retallack, 2008; Dorn, 2009). El clima es un proceso de tipo alocíclico que participa en el control de períodos de actividad geomorfodinámica intensa y de períodos de estabilidad. Los cambios climáticos pueden ser medidos en ciclos temporales variables, que pueden ser sincrónicos, y manifiestan distintos efectos si se trata de décadas, centurias o milenios de un signo (húmedo o seco) determinado (Figura 1). Por otra parte, en los medios áridos y semiáridos, son especialmente importantes los eventos aislados de gran magnitud y baja frecuencia, como por ejemplo lluvias torrenciales excepcionales, que desencadenan respuestas morfodinámicas puntuales capaces de cambiar profundamente la fisonomía y el funcionamiento geomorfológico de un sector. En este caso, es necesario conocer la frecuencia y magnitud de estos eventos (Dorn, 2009).

La tectónica, y las consiguientes variaciones del nivel de base, inducen a cambios en los perfiles de equilibrio de los ríos. Las deformaciones tectónicas que crean subsidencias del nivel de base 
fluvial, generan erosión retrocedente y rejuvenecimiento de cuencas aguas arriba. En el caso contrario, la elevación del nivel de base tiende a generar procesos inversos, favoreciendo la agradación en esos mismos valles o en llanuras litorales (Harvey et al., 2005).

La actividad humana provee una amplia gama de respuestas geomorfológicas (Sampietro-Vattuone y Peña-Monné, 2016; Sampietro Vattuone et al., 2018; Butzer, 2008) que están normalmente relacionadas con cambios en el uso del suelo, tanto en el caso de la colonización de ambientes no ocupados previamente (Hooke, 2000) como cambios producidos por innovación tecnológica así como cambios de los hábitos de ocupación del espacio, como la transición del nomadismo al sedentarismo (Hooke, 2000) y la incorporación y aplicación de técnicas específicas de manejo para la producción y supervivencia (Eitel y Mächtle, 2009; Homburg y Sandor, 2011).

Estos procesos presentan puntos de inflexión cuando alcanzan un umbral geomorfológico en el sentido definido por Schumm (1979). Según el autor, los umbrales son límites de estabilidad paisajística que pueden ser superados por factores intrínsecos del sistema o por un cambio paultino de una variable externa (p. ej. clima, tectónica o cambios de uso). En ambos casos, al superar este umbral se produce un cambio abrupto en la geoforma que puede tener carácter complejo y respuestas incluso opuestas en el corto plazo (como aumentos de las tasas de erosión seguidos de aumentos en la tasa de acumulación como efecto del intento del sistema de alcanzar un nuevo punto de equilibrio) (Schumm, 1979). Tales respuestas complejas muchas veces están relacionadas con la existencia de sistemas geomorfológicos que funcionan de manera acoplada, transmitiendo la disponibilidad de materia y/o energía hacia los extremos del mismo. Estos sistemas acoplados fueron definidos por Brunsden y Thornes (1979) en el marco del estudio de la sensibilidad geomorfológica y reelaborados extensamente por Harvey (2002) en relación a ambientes fluviales. El acoplamiento se relaciona con la conectividad que existe dentro de un sistema geomorfológico y ha sido definido detalladamente en el valle de Tafí (NOA) por Sampietro-Vattuone y Peña-Monné (2016), al establecer el acoplamiento en la evolución sincrónica de laderas, terrazas fluviales y conos aluviales holocenos y su influencia en la ocupación humana de ese espacio. Los sistemas bien acoplados transmiten los efectos de un cambio ambiental a través del conjunto mientras que en el caso de un acoplamiento pobre tales efectos pueden estar restringidos espacialmente o producirse retardos en su transmisión (Harvey, 1997).

En resumen, existen una serie de factores a ser considerados al momento de realizar la interpretación de una zona de interés arqueológico. El hombre hace uso de ese espacio como un territorio indispensable para la supervivencia, inflingiendo un impacto sobre el mismo cuya respuesta dependerá del grado y tipo de actividad así como de la vulnerabilidad del sistema.

\section{Los procesos geomorfológicos y su relación con cambios climáticos en zonas áridas y semiáridas}

En los medios áridos y semiáridos, el clima es uno de los mayores condicionantes para el desarrollo de los procesos geomorfológicos. Pequeñas variaciones en la media de precipitaciones anuales sostenidas a lo largo de unos pocos años o cambios en el régimen estacional de las mismas pueden desencadenar cambios dinámicos de extrema importancia en el corto plazo, estrechamente relacionados con el aumento o disminución de la cobertura vegetal. El desarrollo de un modelo ideal de evolución del medio natural y dinámica geomorfológica ante cambios climáticos (Figura 2) permite observar cuáles son los cambios más relevantes en la biota y el sustrato que se verán luego reflejados en los diversos ambientes que se abordarán y permitirán orientar la búsqueda de proxies y la identificación de la tendencia, húmeda o seca, 

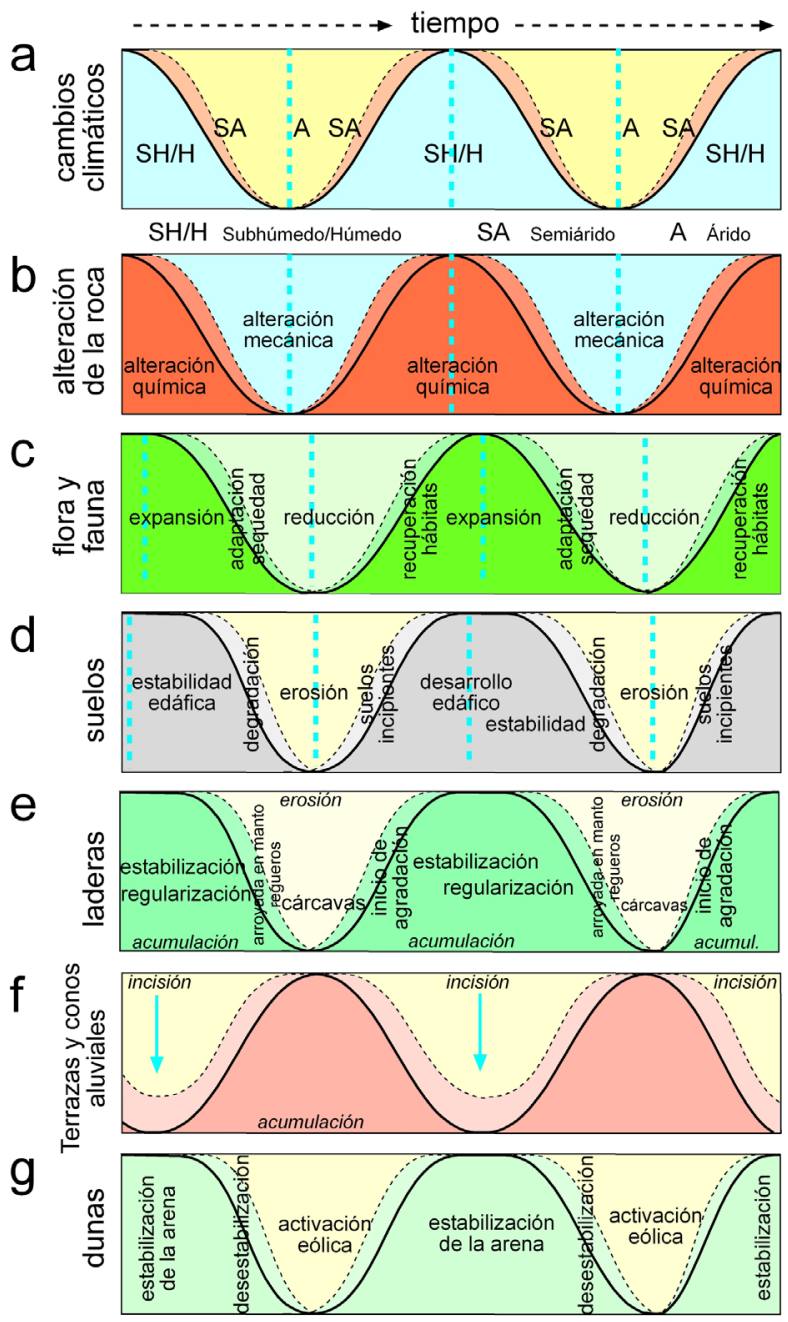

Figura 2 Modelo ideal de evolución del medio natural ante cambios climáticos y diferentes respuestas ambientales; (a) alternancia entre climas húmedos y secos; (b) procesos de alteración de la roca; (c) flora y fauna; (d) suelos; (e) dinámica de laderas; (f) procesos de agradación/incisión en terrazas y conos aluviales; y (g) estabilización/activación de dunas (basado en algunos de sus planteamientos en U.S. Geological Survey's Western Earth Surface Processes Team (2004), en Dorn, 2009).

en cada caso, sumado a posibles retardos en la manifestación del cambio de condiciones según sea la variable observada.

Partiendo de condiciones subhúmedas que cambian hacia ambientes semiáridos y áridos (Figura 2a) podemos observar que en lo relativo a los procesos de alteración de la roca (Figura 2b) existe una transición gradual entre un predominio de procesos de alteración química (disolución, carbonatación, hidrólisis, etc.) a física (diversos mecanismos de fragmentación de la roca) (Caroll, 1970). El predominio de una situación u otra condiciona el tipo de material disponible para su eventual erosión y/o sedimentación determinando resultados geomorfológicos muy distintos. Algunos ejemplos de estos procesos son la formación de costras de carbonatos, barnices y placas parietales formadas por óxidos en superficies rocosas (Goudie, 2004), muy característicos de rocas-soporte de pinturas y grabados rupestres, que en fases más secas se ven afectados por desplacaciones y descamaciones (Peña Monné y Sancho, 2003; Peña Monné y Longares, 2015). Otro ejemplo del efecto de estas alternancias ambientales es la formación de grus por meterorización de rocas plutónicas granudas bajo climas húmedos, que genera una gran disponibilidad de arenas de diversas granulometrías así como también grandes bloques subredondeados para ser transportados en condiciones áridas y formar grandes conos aluviales, como ha sido analizado en el valle de Tafi (Sampietro-Vattuone y Peña-Monné, 2016) o en el valle de Santa María (Peña-Monné y Sampietro-Vattuone, 2016), o la fragmentación de bloques por termoclastía o por gelifracción en pavimentos desérticos, formados previamente en ambientes de otras características. Acompañando a la disminución de humedad del modelo climático, la biota, especialmente la cobertura vegetal, tras un período de adaptación a las condiciones más secas, tiende a disminuir, tanto en cantidad como variedad de especies (Figura 2c). Esto produce también una restricción de hábitats disponibles para la fauna. La pérdida de cobertura vegetal deja la superficie expuesta, permitiendo la mobilización de los materiales finos y/o suelos así como aquellos fragmentados por los procesos de meteorización previamente citados (Figura 2d). Ante una recuperación de humedad, la vegetación gradualmente se recupera, produciéndose sucesiones secundarias con una colonización gradual por especies oportunistas que paulatinamente dan lugar al desarrollo de formaciones vegetales 
a

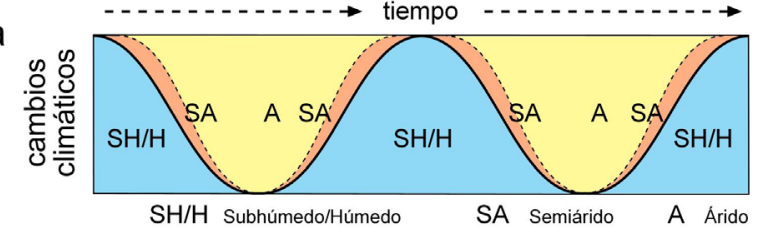

b

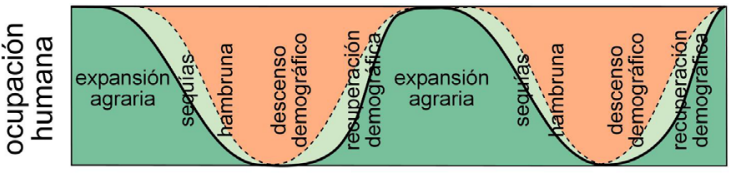

C

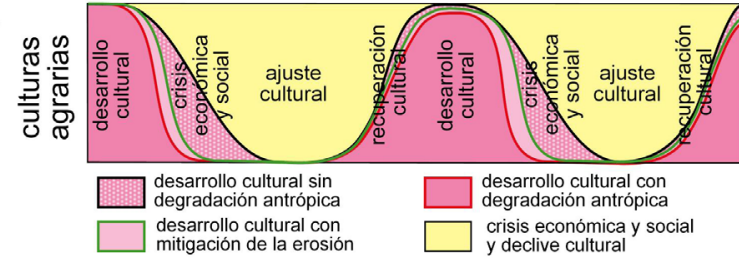

d

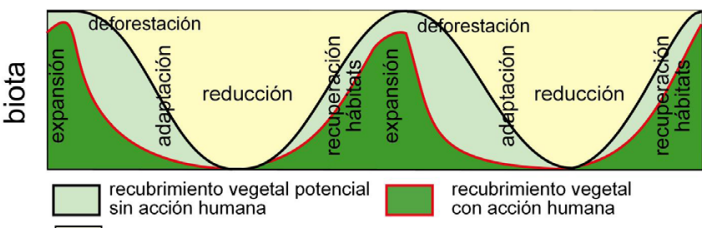

escaso o nulo recubrimiento vegetal

e

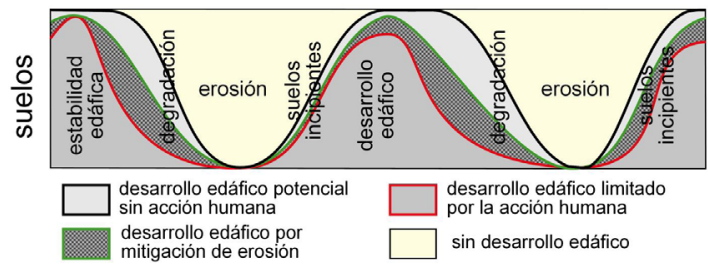

Figura 3 Modelo ideal de evolución ambiental ante cambios climáticos (a) húmedos/secos y respuestas humanas y del medio: (b) ocupación humana; (c) desarrollo de culturas agrarias; (d) biota; y (e) suelos.

maduras, dependiendo del lapso de tiempo de bonanza climática (Lesschen et al., 2008; Maestre et al., 2012).

Las poblaciones humanas también se ven afectadas por estos cambios ambientales (Figura 3a), una gran cantidad de sociedades se asentaron y vivieron en zonas áridas y semiáridas del mundo, y es en estas zonas donde se produjeron innovaciones tan importantes como la domesticación de muchas especies de plantas y animales durante el Holoceno. En términos generales, los períodos de bonanza climática conducen a la expansión de las fronteras agrarias debido, entre otras cosas, a que es posible cultivar a secano tierras que normal- mente no son productivas, más el obvio aumento de las eventuales superficies bajo riego (Figura 3b). Este aumento en la capacidad productiva conlleva normalmente un aumento poblacional, por descenso de la mortalidad, incremento de la natalidad o una combinación de ambos factores. $\mathrm{Al}$ aumentar la población, la presión sobre el ambiente se incrementa gradualmente llevando a alcanzar, en el peor de los casos, el límite de la capacidad de carga (Brooks, 2006).

Ante el establecimiento de condiciones ambientales desfavorables, la capacidad sustentadora del ambiente se deteriora de manera gradual. Normalmente existen medidas tecnológicas (que dependerán de cada sociedad) para mitigar esta situación, hasta alcanzar un umbral por encima del cual la capacidad de sustentación se pierde y es necesaria la implementación de otras respuestas adaptativas, que usualmente van acompañadas de ajustes demográficos (Figura 3b). En este sentido, se han registrado situaciones muy variadas desde procesos de complejización social surgidos como respuesta adaptativa a la aglomeración de población en zonas ambientalmente más favorables, como oasis fluviales (Brooks, 2006), en otros casos se desarrollaron estrategias de diversificación agrícola y aumento del comercio acompañadas por el traslado de la población a posiciones defensivas con construcción de estructuras específicas a este efecto (Zori y Brant, 2012). Incluso ante cambios ambientales de esta naturaleza se verifica la desarticulación y colapso social seguido de una dispersión geográfica de la población (Dillehay y Kolata, 2004). En todos los casos se producen fases de crisis y ajuste social (Figura 3c) (Williams, 2002; Janusek, 2004).

Por otra parte, los períodos húmedos tienden a favorecer los procesos de edafización (Figura 2d). Normalmente, ante cambios hacia condiciones más secas, los suelos mantienen la estabilidad durante un tiempo, protegiendo por tanto la superficie del terreno, reteniendo humedad, materia orgánica y nutrientes, conservando la estructuras de sus agregados, etc., hasta que comienzan a 
degradarse, conservándose parches en zonas protegidas por la vegetación formando en muchos casos pedestales que permiten inferir paleosuperficies (Figura 4a), o zonas más planas donde los procesos erosivos son menores. En presencia de procesos acumulativos, éstos pueden quedar enterrados constituyendo paleosuelos (Figura 4b) que quedan preservados de eventuales procesos degradativos posteriores (Porta Casanellas et al., 2003). La recuperación de las condiciones de humedad lleva a la formación de suelos nuevamente, especialmente vinculados a la recuperación de la vegetación, que es la que produce el mayor aporte de materia orgánica. Estos suelos pueden formarse sobre los relictos de los antiguos generando suelos policíclicos que heredan parte de las características del ambiente pasado, o en superficies que estaban completamente desnudas dando lugar a la formación de un nuevo suelo con características propias del ambiente presente (Porta Casanellas et al., 2003).

Es usual que durante los momentos de expansión agraria, aún bajo períodos de bonanza climática se produzca una expansión restringida de los hábitats de potencial colonización de la biota (Figura 3d). La presión agraria se traduce en deforestación, manipulación del ambiente con fuego y afecciones sobre la superficie de ocupación que limitan la formación de suelos e incluso favorecen su erosión aún bajo condiciones de incipiente formación (Figura 3e). En ambos casos, biota y suelos, su desarrollo potencial se ve limitado por la ocupación humana llevando al establecimiento de umbrales geomorfológicos inferiores a los esperados sin ocupación, aumentando la vulnerabilidad del sistema. Sin embargo, los grupos humanos en muchos casos poseen, dentro de sus capacidades tecnológicas, herramientas para mitigar los efectos negativos del uso del ambiente y potenciar algunos rasgos de interés para la mejora productiva por lo que, de acuerdo con los modelos presentados, pueden definirse márgenes de respuesta cultural que mitiguen o potencien los efectos negativos de las ocupaciones (Figura 3).
Los ámbitos geomorfológicos de las zonas áridas y semiáridas subtropicales que presentan una mejor respuesta ante los cambios ambientales son las laderas, los fondos fluviales y los abanicos aluviales, a los que hay que añadir el viento para los medios más áridos.

Las laderas son superficies inclinadas que se encuentran entre las divisorias de agua y los fondos de valles, que pueden ser sectorizadas según sus componentes y variaciones en la pendiente. Se distinguen laderas desnudas, constituidas esencialmente por la roca de base, o laderas de acumulación de diversas granulometrías (desde grandes bloques hasta arcillas) dependiendo de la pendiente, los procesos acumulativos implicados y los materiales parentales (Small y Clark, 1982; Goudie, 2004). Bajo condiciones húmedas, las laderas tienden a estabilizarse (Figura 2e) produciendo superficies regularizadas sobre las cuales dominan procesos acumulativos de baja energía. Esta situación de equilibrio permite la formación de suelos y repoblamiento vegetal que confieren aún más estabilidad a la geoforma. El paso a condiciones más áridas, con la consiguiente pérdida de cobertura vegetal, lleva al desarrollo de procesos de incisión, inicialmente por arroyada en manto (sheet flood) y regueros (rill wash) que, en caso de persistir las condiciones de aridez, pueden dar por resultado el desarrollo de cárcavas (gullies) (Peña-Monné y Sampietro-Vattuone, 2014).

Con la recuperación de las condiciones de humedad la tendencia se revierte y se producen procesos de agradación de magnitud variable hasta alcanzar nuevamente condiciones de equilibrio. En el caso de procesos erosivos severos con retroceso de los escarpes de cabecera, pueden quedar relictos de laderas estabilizadas aisladas formando facetas triangulares o talus flatiron (Sancho et al., 1988) a partir de los cuales pueden reconstruirse las fases climáticas así como su cronología mediante dataciones absolutas y relativas (Figura 4c). Tanto en el caso precedente como cuando las laderas no han quedado desconectadas de sus cabeceras por los procesos erosivos, las nuevas superficies generadas 

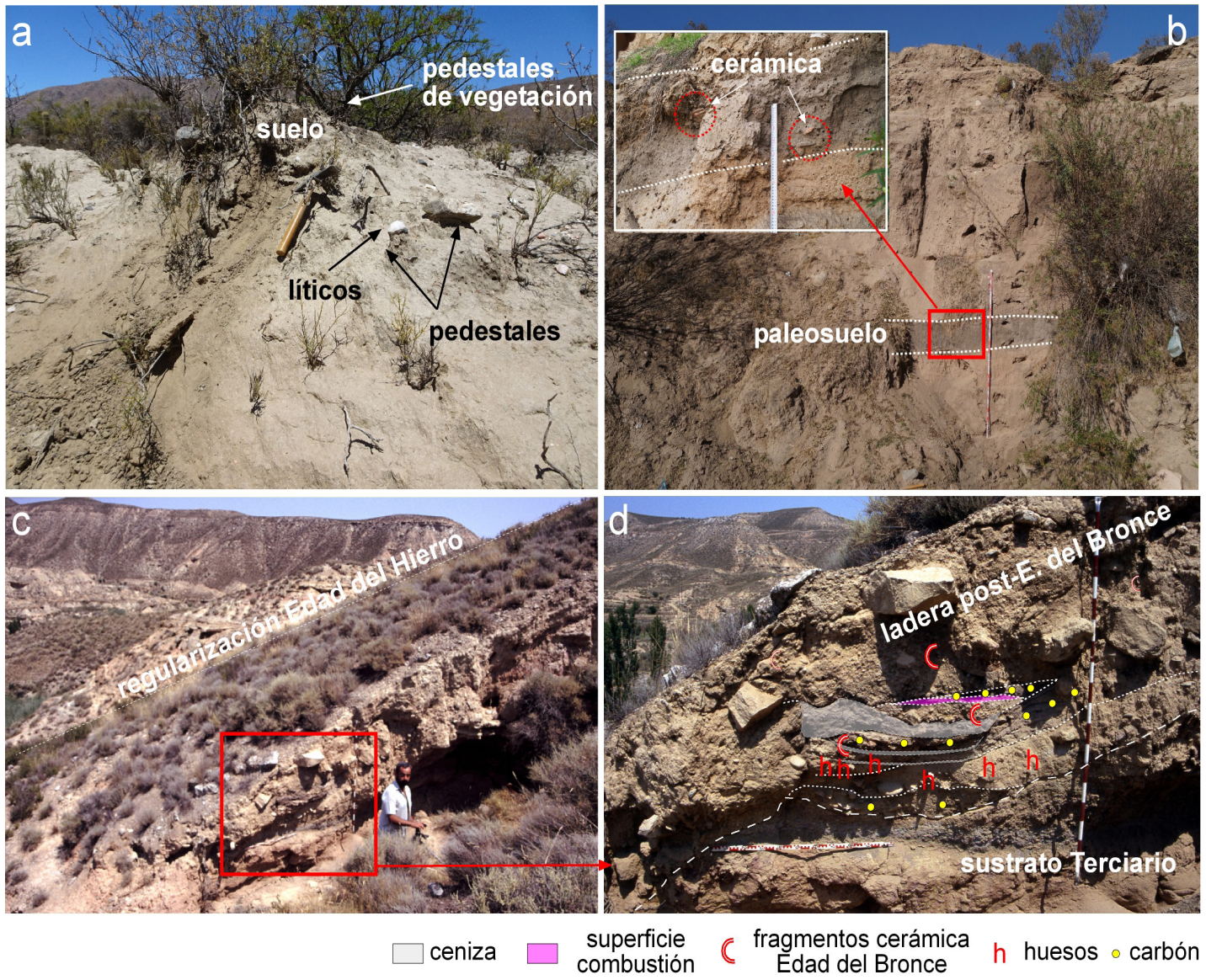

e

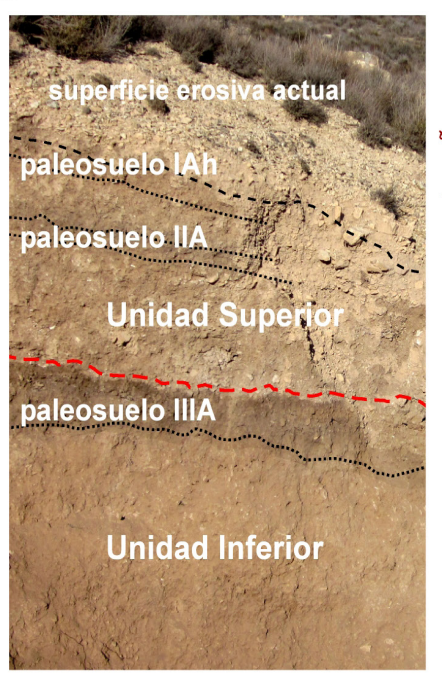

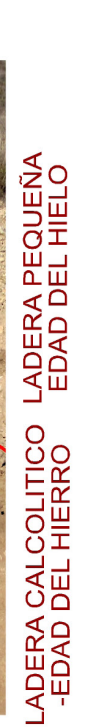

f

- cerámica datada TL

paleosuelo IAh

$1624 \pm 21 A D$
paleosuelo IIA
paleosuelo IIIA
$2152-1995$
cal $A P$

$\pi^{1 \mathrm{~m}} \begin{gathered}4581-4413 \\ \\ \end{gathered}$

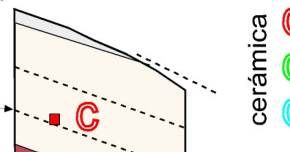

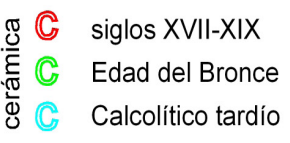

Unidad

superior

Unidad

inferior

$4295-4083$

cal AP

Figura 4 (a) Suelo erosionado formando pedestales favorecidos por la vegetación y por el material arqueológico (Campo Blanco, Tucumán, Argentina); (b) relleno de valle con paleosuelo interestratificado con restos arqueológicos de la Cultura Tafí incluidos (valle de Tafí, Tucumán, Argentina) (según Sampietro-Vattuone y Peña-Monné, 2016); (c) ladera regularizada de la Edad del Hierro; y (d) detalle de los niveles con ocupaciones humanas incorporados durante la fase de acumulación y regularización de la ladera (Budells, Lleida, España) (reelab. de Peña Monné y González, 1992); (e) y (f) acumulación de ladera con tres paleosuelos interestratificados, con fases de ocupación y dataciones desde el Calcolítico tardío y Edad del Bronce hasta la Pequeña Edad del Hielo (Peña Enroque, Zaragoza, España) (reelab. de Pérez-Lambán et al., 2014). 
por agradación pueden enterrar los suelos y superficies de ocupación del pasado dejando evidencia de las condiciones climáticas pasadas incluidas en su estratigrafía (Figura 4d y 4e).

Las laderas se convierten en ámbitos de interés geoarqueológico en cuanto existe una ocupación de estas morfologías durante su evolución, cuyos componentes quedan involucrados en el proceso de las mismas (Figura 4c a 4f). Cuando los suelos generados en etapas más húmedas son aprovechados para actividades agrarias o cuando éstos se ven sometidos a una intervención humana que modifica su dinámica, se generan respuestas similares a las producidas por el clima. Sin embargo, en este caso su acción se inicia directamente sobre la vegetación, que es eliminada por diferentes razones de aprovechamiento y puede verse potenciada cuando además coincide con un cambio climático de tendencia seca, desembocando entonces en procesos de morfogénesis acelerada, de consecuencias mayores (Figura 5a). Estas acciones pueden ser reconocidas a partir del análisis de las acumulaciones correlativas generadas como resultado de dicha acción erosiva en las laderas, que se acaban asentando en el fondo del valle. En el caso de un nuevo cambio en las condiciones de equilibrio que favorezca la incisión del depósito se originarán terrazas fluviales y etapas escalonadas de abanicos aluviales (Sampietro-Vattuone y Peña-Monné, 2016).

Las terrazas fluviales y los abanicos aluviales son formas acumulativas que responden a dinámicas similares, aunque en la primera de estas formas se reduce a espacios restringidos entre paredes marginales de un valle, mientras que los abanicos aluviales adoptan morfología expansiva debido a la apertura que experimentan al abrirse el curso hacia otro valle más amplio o depresión. Por ello, los conos o abanicos aluviales son cuerpos de depósitos fluviales cuya superficie es aproximadamente un segmento de cono que se extienden radialmente desde el punto en que el curso de agua se aparta del frente montañoso (Bull, 1968). Por su parte, las terrazas fluviales son superficies planas compuestas por un rellano y un escarpe que formaron parte de la llanura de inundación de un río, del que quedaron separadas tras un proceso de incisión. Mientras las acumulaciones se deben a procesos de fuerte aluvionamiento durante etapas de mayor caudal y por tanto mayor descarga fluvial, la incisión se produce en condiciones más secas en que disminuye el flujo de agua y su energía se concentra en un cauce estrecho, que va profundizando (Figura 2f). Estos cambios en la competencia fluvial pueden deberse tanto a simples fluctuaciones climáticas húmedas/secas como a cambios más importantes como son los ciclos glaciares/interglaciares. Como consecuencia de estas alternancias ambientales, las terrazas aparecen en el paisaje en forma de escalones de distintas edades que se van sucediendo de más antiguos a más recientes hasta el fondo el valle actual (Figura 5b). Los abanicos aluviales responden a una dinámica semejante, adoptando formas segmentadas también llamadas dispositivos prismáticos, existiendo en estos casos, además de desencadenantes climáticos, una relación directa con cambios del nivel de base por causas tectónicas (Bull, 1968; Harvey et al., 2005).

Estas dos morfologías tienen de igual manera un gran interés para las investigaciones geoarqueológicas en zonas áridas y semiáridas, al tratarse de áreas cercanas al agua y por tanto sectores de un gran atractivo para la instalación humana. Es por ello que los contextos fluviales, tanto de ríos bien estructurados de carácter permanente como otros más efímeros y de dinámica torrencial, contienen los mejores registros con información geoarqueológica. En el sector central de la depresión del Ebro, en el Nordeste de España, en condiciones semiáridas, la mayor parte de los sitios arqueológicos de las Edades del Bronce y Hierro y de la cultura Ibérica han sufrido una intensa erosión. Instalados en relieves escarpados de materiales blandos (yesos y arcillas), estos sitios arqueológicos han ido perdiéndose la mayor parte de sus estructuras habitacionales y murallas defensivas a medida que la degradación del paisaje progresaba como consecuencia de la sobreexplotación generada principalmente en épocas Ibérica y Romana 
a
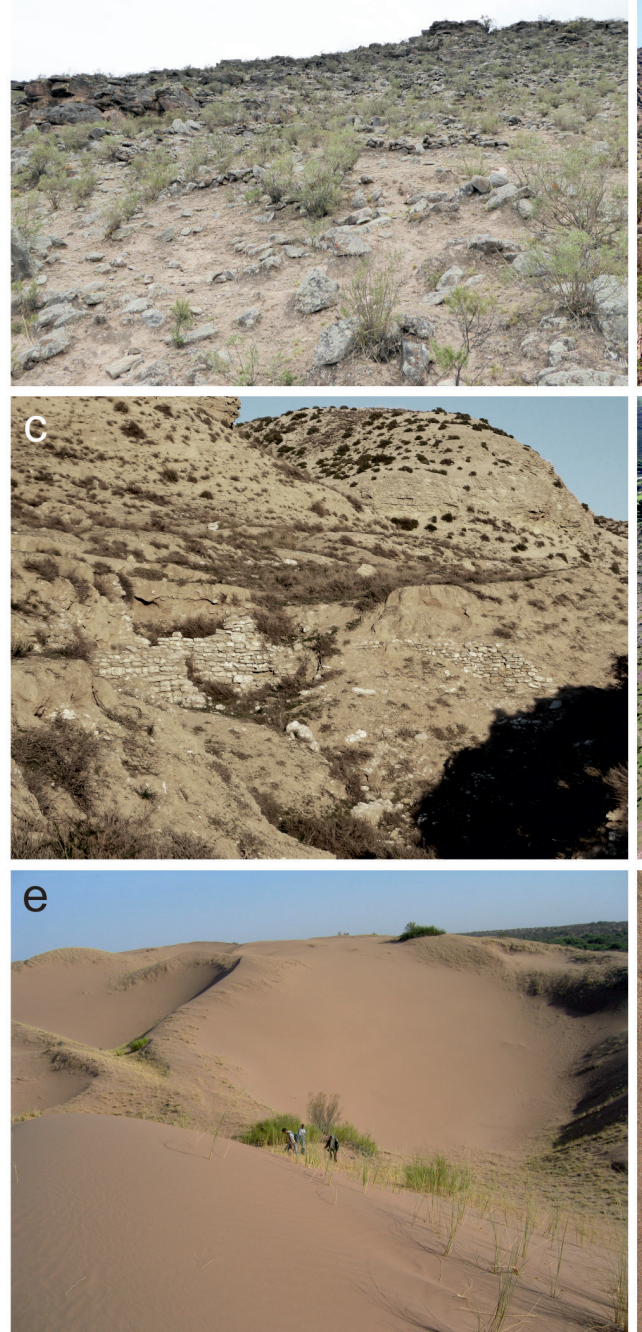

b
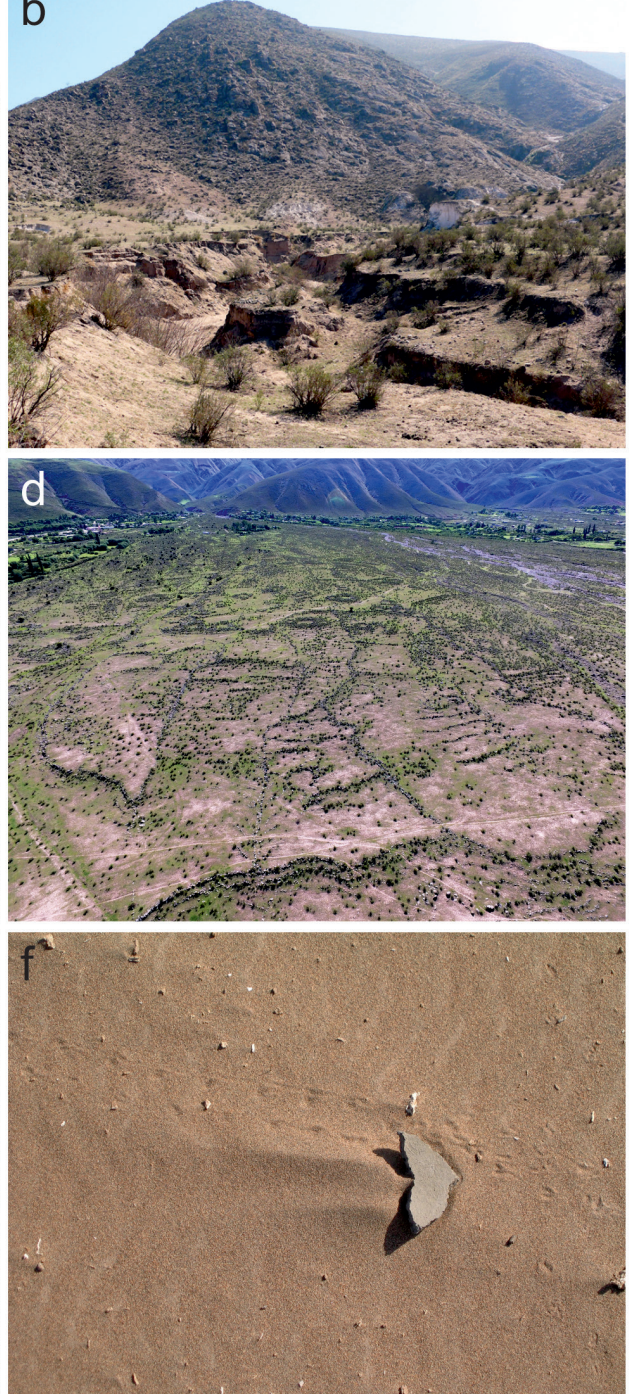

Figura 5 (a) Laderas sistematizadas para agricultura prehispánica afectadas por la erosión (valle de Tafí, Tucumán, Argentina); (b) sistema de terrazas fluviales holocenas escalonadas, con diferenciación de cuatro etapas evolutivas (valle de Tafí, Tucumán, Argentina); (c) casas de Época lbérica y Romana enterradas por los rellenos de fondo de valle post-romanos, incididos posteriormente por los barrancos (Mediana de Aragón, Zaragoza, España); (d) estructuras residenciales y agrícolas sobre el abanico aluvial de La Costa (valle de Tafí, Tucumán, Argentina); (e) blow-out por deflación eólica exhumando las ocupaciones huarpes (Lavalle, Mendoza, Argentina); y (f) detalle de los restos de cerámica, espinas de pescado y otros elementos arqueológicos en estas mismas dunas.

(siglos V AC a V AD) (Peña Monné, 1996; Pérez-Lambán et al., 2014; Peña Monné et al., 2018). Hoy día, sólo es posible reconstruir el poblamiento de esas épocas a través del estudio geoarqueológico de los registros sedimentarios en terrazas y abanicos aluviales holocenos. En esas mismas circunstancias erosivas, las villae romanas instaladas en la mayor parte de los abanicos aluviales a partir del siglo II - IV AD, desaparecieron bajo la capa de sedimentos, de manera que son visibles únicamente en las incisiones posteriores de los barrancos (Peña Monné et al., 2004) (Figura 5c). A pesar de la distancia que los separa, en el valle de Tafí (provincia de Tucumán, Argentina) se generaron idénticas circunstancias de degradación ambiental a causa de la fuerte ocupación y explotación agraria del valle por la cultura Tafi (ca. $360 \mathrm{AC}-1000$ $\mathrm{AD})$, que no generó la desaparición de las cons- 
trucciones ocupacionales, situadas sobre las superficies de los abanicos aluviales holocenos gracias al gran tamaño de los bloques utilizados (Figura 5d), pero dio lugar a las acumulaciones de los niveles superiores de las terrazas y abanicos aluviales de la fase H2 definida por Sampietro Vattuone y Peña Monné (2016) y Peña Monné y Sampietro Vattuone (2016) y que incluye restos arqueológicos de dicha época (Figura 4b).

Finalmente, en los ambientes áridos también es muy importante la acción del viento sobre espacios con nula o escasa protección de la vegetación. Su acción está además mediatizada por el tamaño del grano, la existencia de inundaciones estacionales, la superficialidad de los mantos freáticos, protección de la pedregosidad (pavimentos desérticos), velocidad y direcciones de vientos dominantes, etc. Desde el punto de vista erosivo, pueden formarse corredores de deflacción, yardangs y blowouts, mientras que las formas acumulativas más corrientes son los mantos eólicos y los campos de dunas (Figura 5e y 5f), que pueden llegar a formar grandes campos dunares (ergs).

Dado que la disponibilidad de sedimentos para ser transportados por el viento depende de su contenido de humedad, cubierta vegetal, encostramiento biológico y cohesión (Goudie, 2004), las condiciones ambientales y variabilidad climática son factores importantes a tener en cuenta en la dinámica eólica. En situaciones de mayor humedad, las dunas y los mantos eólicos tienden a fijarse, pero el cambio hacia condiciones más secas produce desestabilización en la medida en que la vegetación pierde su capacidad fijadora y las costras biológicas que puedan haberse desarrollado pierden cohesión por la acción erosiva del viento. Lo mismo sucede con eventuales suelos que pudieran haberse formado durante períodos de disponibilidad de humedad (Figura $2 \mathrm{~g}$ ). La pérdida de estabilidad lleva a períodos de activación eólica que se mantienen aún después de una relativa recuperación ambiental. Esta sucesión ambiental alternante se produce también en ocasiones por una fuerte presión humana sobre espacios fijados climáticamente con anterioridad por la vegetación. De manera que la ocupación por el hombre de ambientes favorables a la activación eólica por sus características de tamaño de grano y frecuencia de vientos de altas velocidades puede desencadenar la desaparición de un área que anteriormente tuvo elementos favorables para su ocupación (Figura 5f). No siempre es fácil determinar cuál es el papel del hombre en las reactivaciones dunares durante el Holoceno, como ha sido puesto de manifiesto por Peña-Monné et al. (2015) en los campos de dunas de Cafayate (Salta, Argentina), en donde se han definido 4 etapas de reactivación dunar durante los últimos 1000 años, de la que solamente la última (siglo XVIII) parece responder a causas antrópicas relacionadas con una sobreexplotación del espacio durante un periodo de tiempo para el engorde de ganado mular para la minería del Alto Perú. Sin embargo, es posible ver en corredores y blow-outs producidos puntualmente por fuerte deflación eólica los restos materiales de ocupaciones humanas, que reaparecen tras haber sido sepultados por la arena en fases anteriores de reactivación dunar, como en el caso de las dunas de Lavalle (Mendoza, Argentina) (Figura 5e y 5f) o de Cafayate (Salta, Argentina) (Peña-Monné et al., 2015).

\section{Propuesta metodológica}

Tal como se desprende de la exposición anterior, existen una serie de variables articuladas entre sí que deben ser tenidas en cuenta para comprender la evolución global de una zona de interés arqueológico y su propio contexto, tanto como resultado de actividades humanas directas como de su evolución a largo plazo para formar parte del paisaje que llega a nuestros días. Desde un punto de vista metodológico se pueden proponer una serie de pasos dirigidos a obtener la información disponible, articularla e interpretarla en su contexto local, regional y global. Esta posibilidad de 


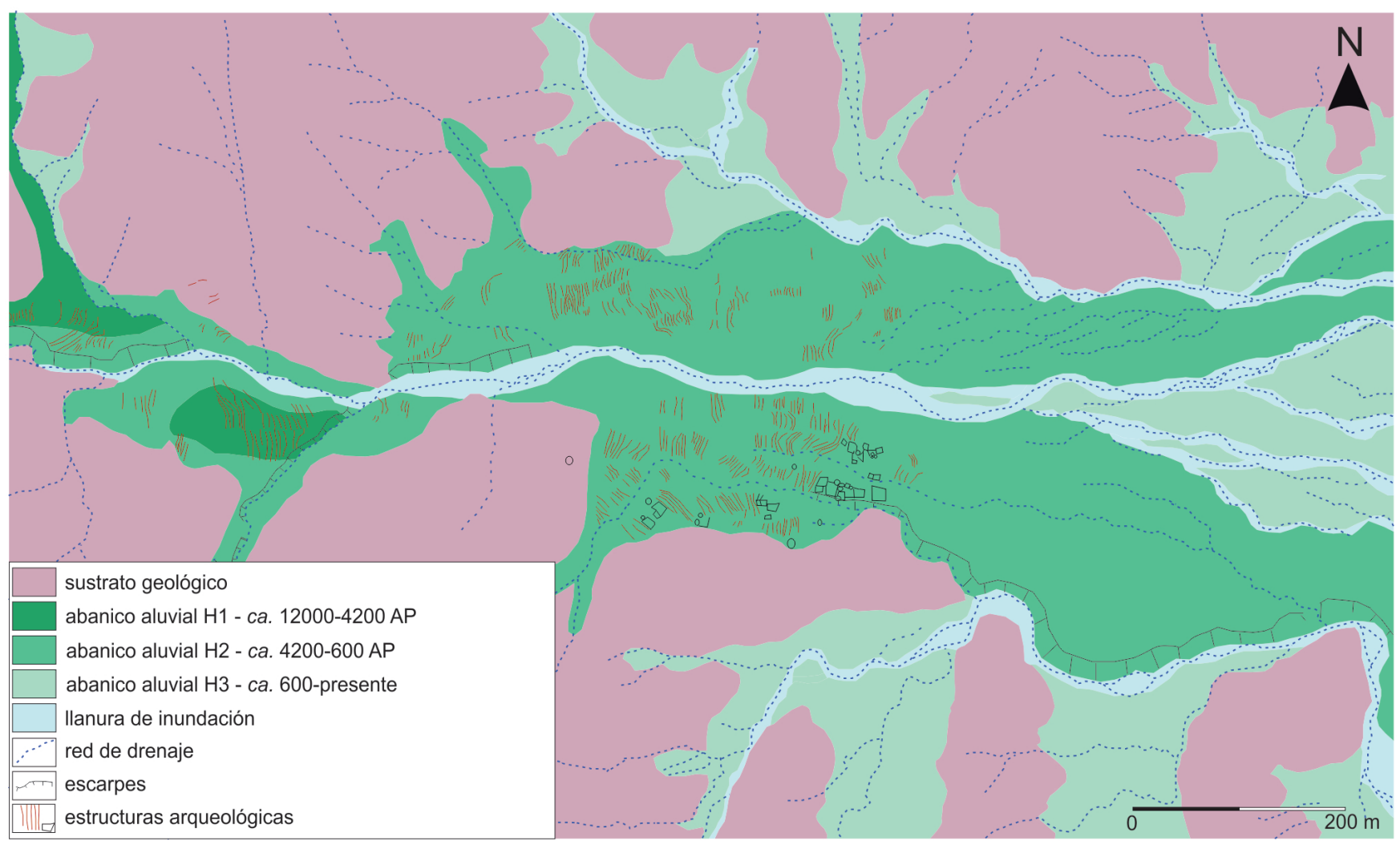

Figura 6 Mapa geomorfológico del ápice del abanico aluvial de Las Cañas (Tucumán, Argentina) donde se diferencian las principales unidades morfosedimentarias holocenas y las estructuras arqueológicas más sobresalientes correspondientes a zonas residenciales y terrazas agrícolas.

manejar diversas escalas temporales y espaciales otorga riqueza a las interpretaciones y una mejor perspectiva, tanto desde lo natural como de lo cultural, que se plantean como un conjunto único de fuerzas que actúan de manera sinérgica.

En primera instancia, el estudio conjunto de los diversos componentes geomorfológicos del paisaje es necesario. En este sentido, la cartografia geomorfológica adquiere una mayor utilidad ya que permite establecer referencias espaciales de las formas de relieve de un territorio y definir sus distintas unidades morfosedimentarias. Además, estos mapas pueden aglutinar la información arqueológica de la distribución de estructuras y sitios permitiendo establecer relaciones directas entre ambos aspectos (Figura 6). El establecimiento de unidades morfosedimentarias implica la búsqueda, descripción y análisis de secuencias sedimentarias representativas de la evolución geomorfológica de cada zona en los ambientes presentes en el área de estudio, estableciendo la vinculación existente entre ellos (Figura 7). La información espacial (mapa geomorfológico), estratigráfica (perfiles estratigráficos) y cronológica (dataciones, niveles guía) de estas unidades morfosedimentarias se complementa con la elaboración detallada de perfiles transversales y longitudinales de los valles analizados (Figura 7a, 7b, 7d y 7e) y de perfiles estratigráficos detallados (Figura 7c y 7f) La información registrada en cada uno de los perfiles descritos, que son reflejo de los componentes del sistema, contiene rasgos específicos de cada corte pero también elementos que pueden ser comunes entre varios de ellos y permitir su correlación espacio-temporal.

Con objeto de llegar a obtener una secuencia cronológica general es necesario prestar atención a la presencia y registro en contexto estratigráfico 
de materiales arqueológicos datables (o de edades conocidas, como fragmentos cerámicos de tipos concretos) en cada una de las secuencias sedimentarias (Figura 7f). Tales perfiles ayudan a visualizar la disposición topográfica relativa de las unidades identificadas a lo largo y ancho de la unidad geomorfológica y deben integrar la información cronoestratigráfica para reconstruir una secuencia de formación de dichas unidades. Es normal que se reconozca entonces la existencia de unidades acopladas de laderas/terrazas/conos que mantienen correlaciones laterales, dada su sincronía y conexión interna entre las formas. De igual manera, debe constatarse la presencia de paleosuelos y/o capas carbonáticas u orgánicas interestratificadas, o bien horizontes de referencia con edades ya establecidas (como capas de cineritas de composición geoquímica correlacionables) (Figura 7c), entre otros. Estos proveen un control cronológico independiente, útil para la reconstrucción final. La información arqueológica obtenida por métodos tradicionales, como prospección, registros de detalle o semidetalle, cartografía de estructuras arqueológicas, excavaciones, etc., debe ser integrada en la cartografía geomorfológica y correlacionada con los perfiles morfoestratigráficos realizados. Lo anterior permite una correcta contextualización en el marco interpretativo general de la evolución del sitio y de las características de las afecciones producidas localmente por la actividad humana.

Por otra parte, rasgos como la presencia de suelos, etapas de estabilización de laderas o momentos de fijación de dunas proporcionan evidencias de tendencias climáticas húmedas que, con los controles cronológicos previamente descritos, deben ser puestos en su contexto regional y global tomando en cuenta las reconstrucciones y datos ya validados existentes. Lo mismo con la identificación de etapas de ruptura a condiciones ambientales más secas manifestadas por incisiones o intensificación de la erosión subsuperficial, o bien reactivaciones dunares que puedan relacionarse con cambios climáticos o impactos antrópicos. Esto proporciona un marco de referencia más amplio que permite contextualizar la reconstrucción final en una escala superior a la del sitio arqueológico y facilita la interpretación de procesos evolutivos socioculturales y ambientales de gran escala.

A modo de ejemplo, en el valle de Tafí (Tucumán, Argentina) la diferenciación de tres capas de cenizas volcánicas interestratificadas en las acumulaciones de valle, abanicos aluviales y laderas holocenas (Sampietro-Vattuone y Peña-Monné, 2016; Sampietro Vattuone et al., 2017) ha permitido, una vez obtenida su cronología, establecer correlaciones incluso más allá del valle, alcanzando la llanura de Tucumán y el valle de Santa María, dada la amplitud del área de dispersión de tefras que tuvieron algunas de las erupciones, como la de Cerro Blanco (Fernández-Turiel et al., 2013). En otro contexto distinto, como el del Nordeste de la Península Ibérica, la presencia de laderas estabilizadas morfológicamente y con desarrollo de paleosuelos, bien datados por material arqueológico específico y otros métodos clásicos (Burillo et al., 1981; Peña Monné et al., 1996, 2005; Pérez-Lambán et al., 2014), permitieron establecer correlaciones de carácter suprarregional para una etapa húmeda y fría como la de la Edad del Hierro, que a nivel global se identifica con el Evento Bond 2.8 (Bond et al., 1997), cifra que se refiere a la edad en miles de años BP de su momento máximo, obtenida en los registros del fondo marino del Atlántico Norte y manifestada por un mayor dinamismo del transporte en icebergs de minerales y terrígenos desde Terranova y Groenlandia hacia el sur. Quizás el mayor desafío en este procedimiento sea el establecimiento de una correcta correlación estratigráfica articulada con los perfiles transversales y longitudinales. La suma de rasgos incluídos en los cortes descritos (incluyendo aquellos arqueológicos en sentido estricto) refleja necesariamente si existen retardos en la expresión de cambios ambientales rápidos o resistencia del sistema geomorfológico a alcanzar umbrales de vulnerabilidad que normalmente se manifiestan como rupturas morfoestratigráficas y geomorfológicas. Es usual que estas rupturas aparezcan de manera 
a

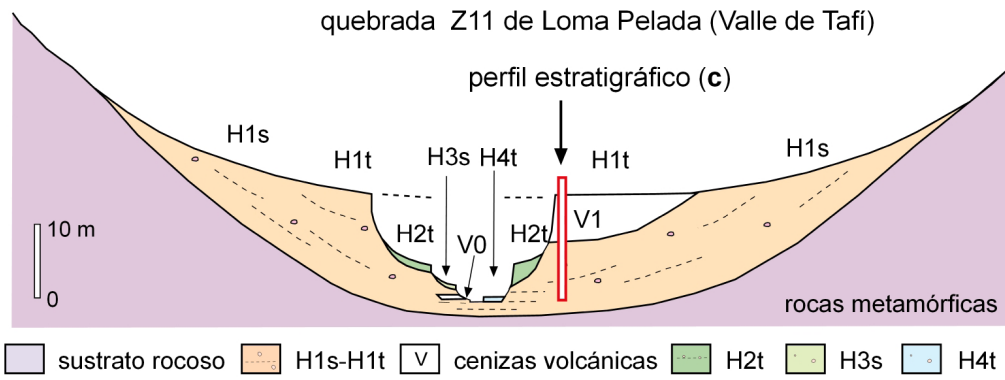

b

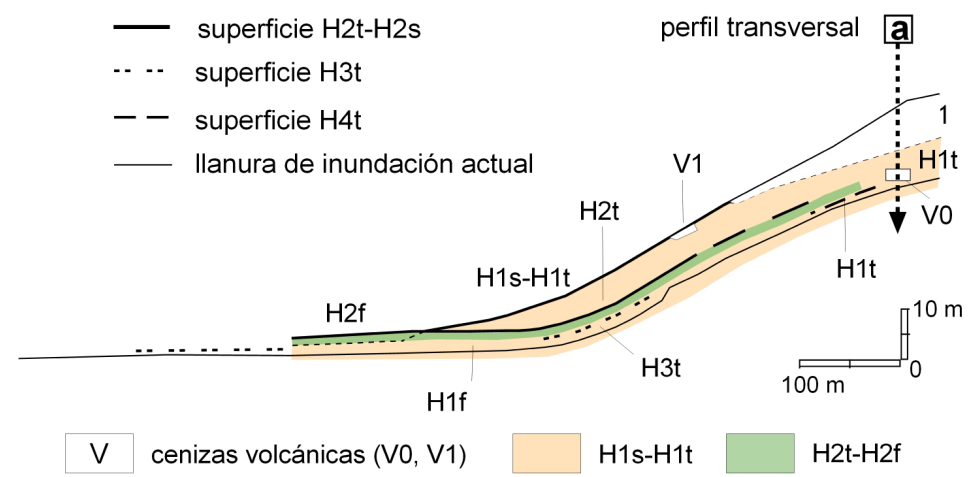

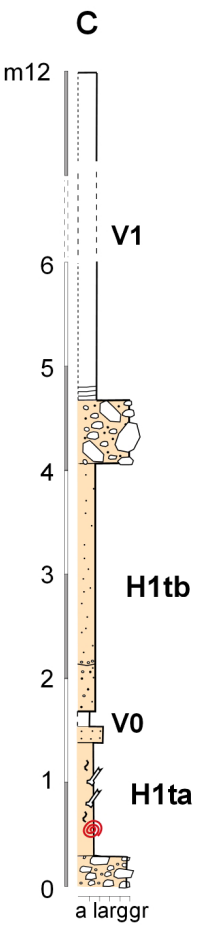

a: arcillas; I: limos; ar: arena g: gravilla; gr:gravas d

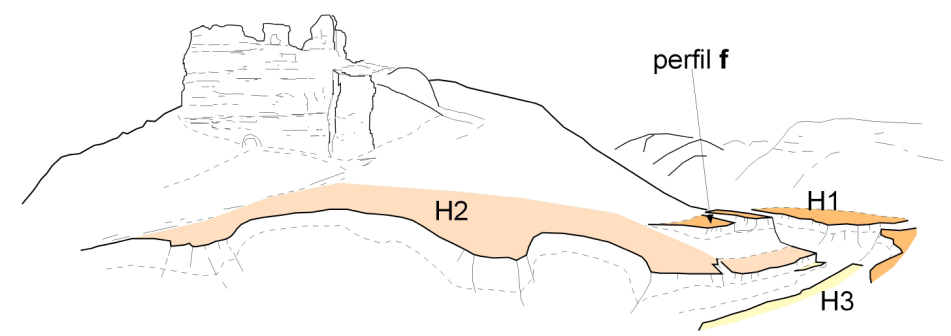

e

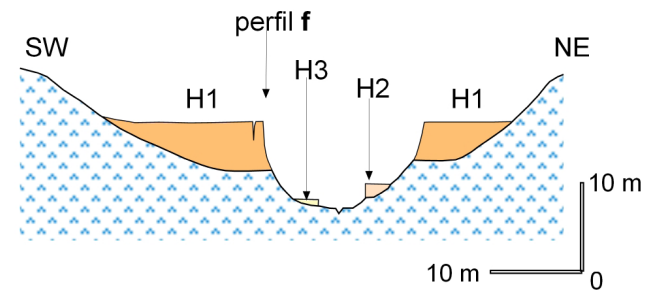

\section{$f$}

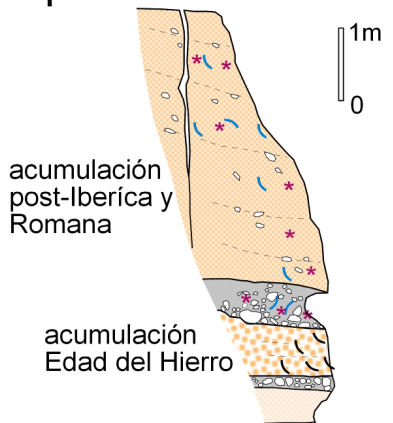

acumulación pre-Edad del Hierro

( cerámicas Edad del Hierro

( cerámicas romanas

- cerámicas medievales

* carbón

Figura 7 Perfiles significativos para los trabajos geoarqueológicos en fondos de valle, partiendo de la diferenciación de unidades morfosedimentarias holocenas: (a) perfil transversal de uno de los valles de Loma Pelada (valle de Tafí, Tucumán, Argentina); (b) perfil longitudinal del mismo valle mostrando la disposición de los diferentes niveles; (c) perfil estratigráfico detallado de un punto del valle, con la información sedimentaria, la diferenciación de unidades y la posición de los principales indicadores paleoambientales (reelab. de Peña-Monné y Sampietro-Vattuone, 2016); (d) esquema de los rellenos del valle de un pequeño afluente del río Ebro, cerca de Zaragoza (España), al pie de un sitio arqueológico ocupado desde la Edad del Hierro hasta Época Medieval; (e) perfil transversal del valle ; (f) perfil estratigráfico e interpretación de sus registros geoarqueológicos (reelab. de Peña Monné, 1996). 


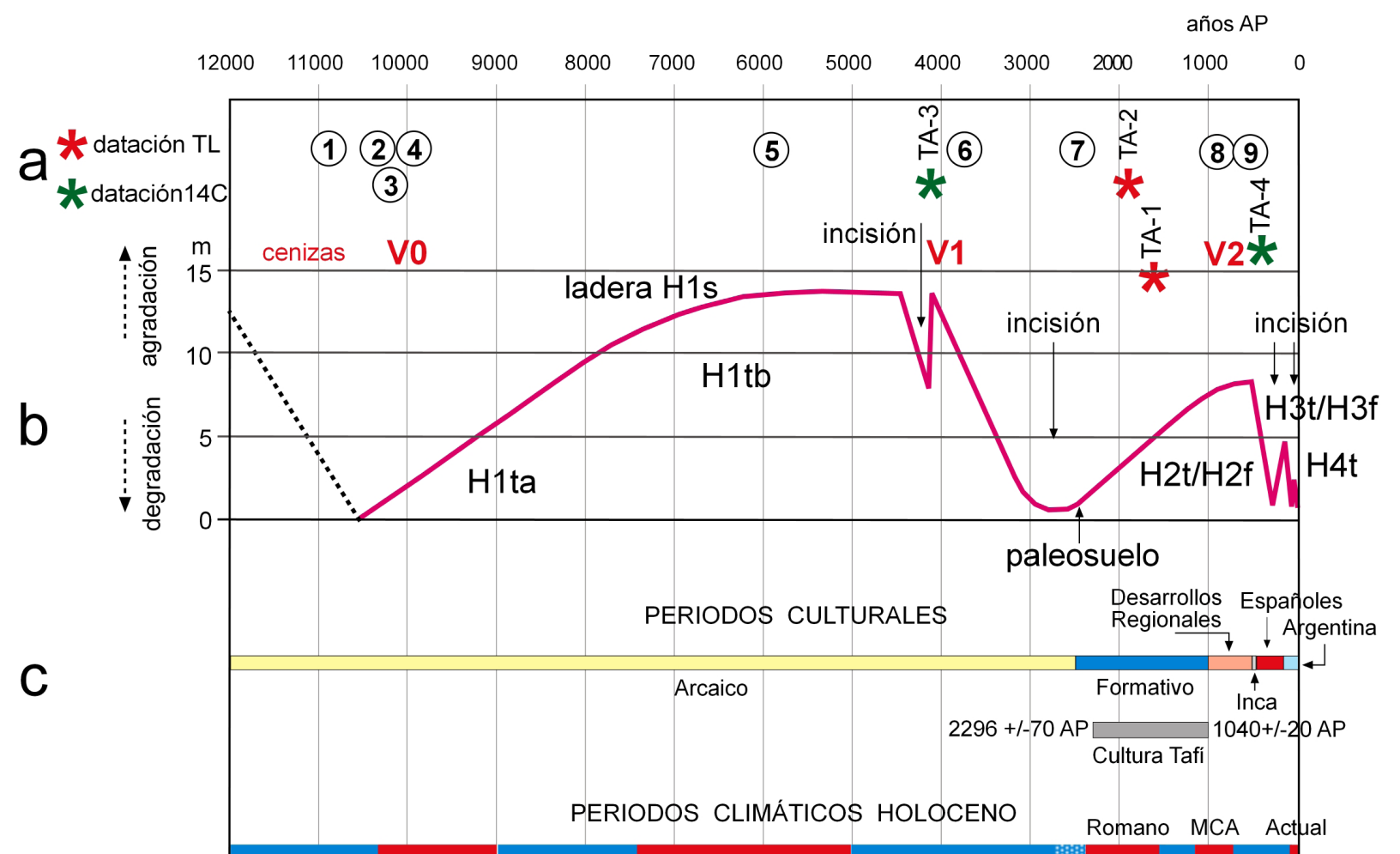

d

\begin{tabular}{|c|c|c|}
\hline $\begin{array}{c}\text { Fini-Glacial Pre-Boreal } \\
\text { HOLOCENO INFERIOR }\end{array}$ & $\begin{array}{c}\text { Atlántico } \\
\text { HOLOCENO MEDIO }\end{array}$ & $\begin{array}{c}\text { Subboreal } \\
\text { E. Hierro Dark Age PEH } \\
\text { HOLOCENO SUPERIOR }\end{array}$ \\
\hline
\end{tabular}

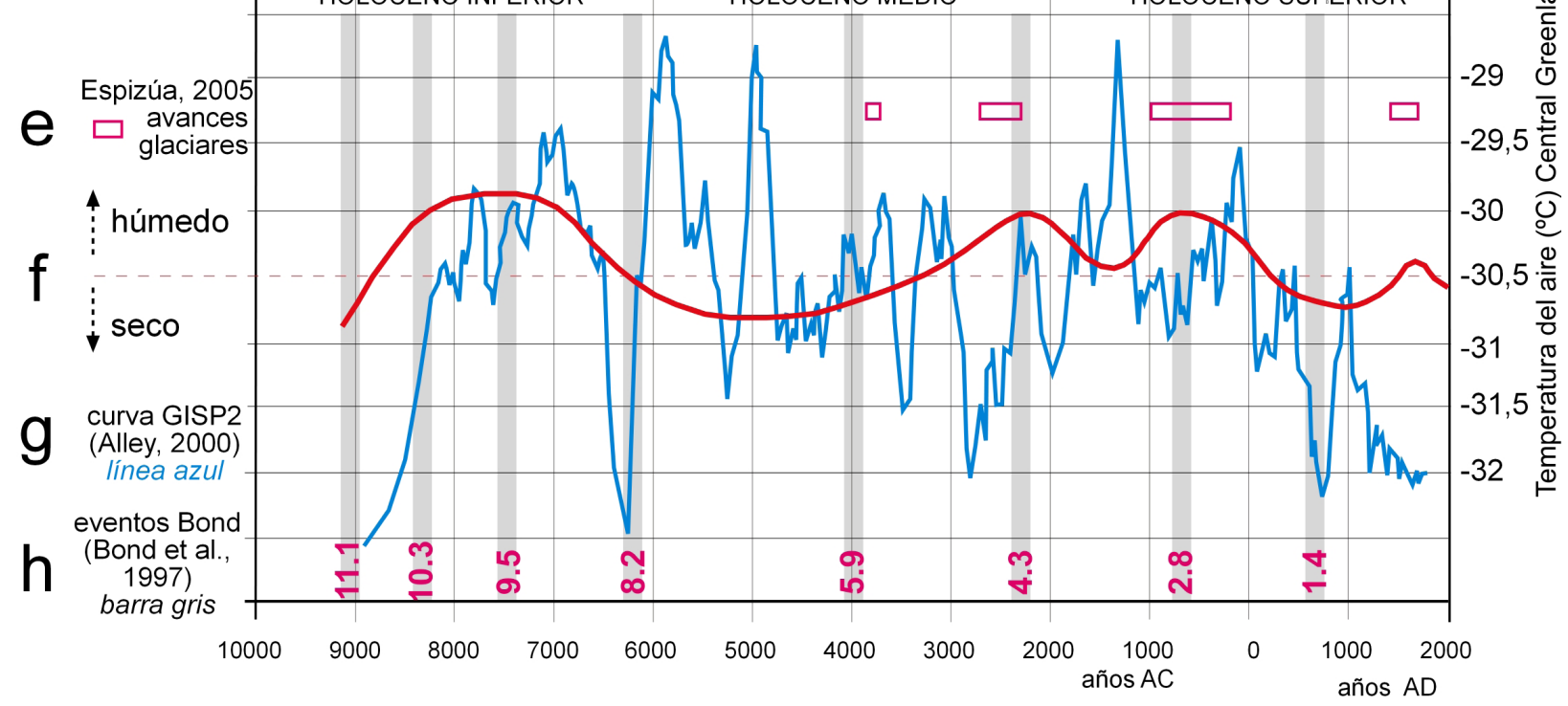
(1) $10870+/-290$ cal AP Fink, 2001 (en Hermanns et al., 2006)

(2) $10350+/-80 \mathrm{AP}$
Garralla et al., 2001

(3) $10250-9650 \mathrm{cal}$ AP
Ortiz y Jayat, 2007

(4) $9980+/-60 \mathrm{AP}$

(5) $5950+/-90 \mathrm{AP}$ Sayago et al., 1991

(6) $4290+/-40 \mathrm{AP}$ Fernández-Turiel et al., 2013

(7) $2480+/-110 \mathrm{AP}$ Sampietro Vattuone, 1999
(8) $1010+/-80 \mathrm{AP}$ Peña-Monné et al., 2015
(9) $435+/-15 \mathrm{AP}$ Sayago et al., 2012

Figura 8 Modelo evolutivo reuniendo toda la información disponible de carácter local y regional de un sector del valle de Tafí, Tucumán, Argentina) y su relación con indicadores paleoambientales globales: (a) datos cronológicos; (b) etapas morfosedimentarias de agradación e incisión; (c) relación con etapas culturales del NOA; (d) relación con periodos climáticos globales del Holoceno; (e) relación con las fases glaciares de los Andes de Mendoza; (f) reconstrucción tentativa de etapas húmedas/secas; (g) y (h) datos paleoambientales de la Curva GISP 2 y eventos Bond, respectivamente, como elementos de correlación global de etapas frías/cálidas (Peña-Monné y Sampietro-Vattuone, 2016). 
rápida en contextos de ocupación humana, por ejemplo manifiestas como procesos de morfogénesis acelerada. Todo ello a pesar de que se hayan podido aplicar medidas de mitigación por parte de las comunidades del pasado, como puede ser la construcción de terrazas agrícolas (algunos ejemplos de estos procesos de morfogénesis acelerada pueden ser revisados en Sampietro-Vattuone y Peña-Monné (2016) y Peña Monné et al. (2018). La correcta comprensión de los sistemas geomorfológicos analizados permite inferir cuán rápido impacta un cambio ambiental (incluyendo factores naturales y humanos) en el mismo. Los ajustes se manifiestan en cambios del sistema de pendientes y drenaje, la cubierta vegetal, los índices de erosión, la disponibilidad de sedimentos almacenados para movilizarse a medida que se producen desestabilizaciones, entre otros. La naturaleza de las discontinuidades entre clima/vegetación/actividad humana se constituyen en un factor clave del proceso de articulación e integración de todos los resultados.

El último componente de esta propuesta es la construcción final de un modelo interpretativo que dé cuenta de la evolución de todos los procesos implicados. En otras palabras, la información arqueológica de la zona de estudio, su deriva ambiental, los procesos morfogenéticos implicados con sus correspondientes rupturas, el marco temporal relativo y absoluto, y su contextualización en un arco regional y global, sumado a la explicación de las causas y efectos de las ya citadas rupturas. En este sentido, es de gran utilidad la construcción de diagramas en los que se refleje la información local y su relación con los datos paleoambientales de alcance regional o global, que en ocasiones permiten refrendar la bondad de las interpretaciones a escala local y manejar simultáneamente diferentes escalas temporales y espaciales (Figura 8).

\section{Conclusiones}

La metodología propuesta, basada en un largo periodo de experimentación en ambientes áridos y semáridos, consiste esencialmente en cuatro pasos fundamentales, donde la actividad humana y posterior información arqueológica se integra constantemente como parte esencial de los procesos de formación. Los datos cronológicos son parte sustancial del esquema de representación, permitiendo una interpretación global de los sitios de interés arqueológico en múltiples dimensiones espaciales, temporales y sociales. Estos pasos pueden resumirse en: 1) construcción de mapas geomorfológicos que contengan la información arqueológica cartografiable y la identificación de las unidades morfosedimentarias más representativas, 2) descripción de las unidades morfosedimentarias y establecimiento de las relaciones espaciales y evolutivas de las mismas integrando la información arqueológica, cronológica y paleoambiental disponible, 3) registro de los perfiles longitudinales y transversales de la zona de estudio que integren toda la información permitiendo además establecer sincronicidades y retardos en la manifestación de los procesos humanos y naturales en las diversas unidades, 4) realización de diagramas de síntesis que involucren toda la información disponible a nivel local, regional y global. El éxito de esta metodología dependerá de la calidad de la información recuperada y de las posibilidades de establecer relación entre todos los datos recolectados. Tal como está planteada, ofrece sin duda una oportunidad inigualable para lograr esquemas sintéticos comprehensivos y con un detalle adecuado a la calidad y cantidad de información disponibles según el avance de la investigación. 


\section{Referencias}

Bintliff, J., 2005, Human impact, land-use history, and the surface archaeological record: A case study from Greece: Geoarchaeology, 20(2), 135-147.

Bond, G., Showers, W., Cheseby, M., Lotti, R., Almasi, P., deMenocal, P., Priore, P., Cullen, H., Hajdas, I., Bonani, G., 1997, A pervasive millennial-scale cycle in north Atlantic Holocene and glacial climates: Science, 278, $1257-1266$.

Brooks, N., 2006, Gultural responses to aridity in the Middle Holocene and increased social complexity: Quaternary International, 151, 29-49.

Brückner, H., 1998. Coastal research and geoarchaeology in the Mediterranean region. German geographical coastal researchThe last decade. Institute for Scientific Cooperation, Tübingen and Committee of the Federal Republic of Germany for the Int. Geographical Union: Tübingen, 235-258.

Brunsden, D., Thornes, J.B., 1979. Landscape sensitivity and change. Transactions of the Institute of British Geographers, 463-484.

Bull, W.B., 1968. Alluvial fans: Journal of Geological Education, 16(3), 101-106.

Burillo, F., Gutiérrez, M., Peña,J.L., 1981, El cerro del castillo de Alfambra. (Teruel): Kalathos, 1, 7-63.

Burillo, F., Peña Monné, J.L., 1984, Clima, geomorfología y ocupación humana. Introducción a un planteamiento metodológico: Actas la Jornadas de Metodología de Investigación Prehistórica: Soria 1981, 91-102.

Butzer, K.W., 2005. Environmental history in the Mediterranean world: cross-disciplinary investigation of cause-and-effect for degradation and soil erosion: Journal of Archaeological Science, 32(12), 1773-1800.
Butzer, K.W., 2008, Challenges for a crossdisciplinary geoarchaeology: the intersection between environmental history and geomorphology: Geomorphology, 101(1-2), 402-411.

Carroll, D., 1970, Rock Weathering: Nueva York, U.S.A., Plenum Press.

Dillehay, T., Kolata, A.L., 2004, Pre-industrial human and environment interactions in northern Peru during the late Holocene: The Holocene, 14(2), 272-281.

Dorn, R.I., 2009, The role of climatic change in alluvial fan development, en Parsons, A.J., Abrahams, A.D. (eds.), Geomorphology of desert environments, 2nd edition: Nueva York, U.S.A., Springer, 723-742.

Eitel, B., Mächtle, B., 2009, Man and environment in the eastern Atacama Desert (southern Peru): Holocene climate changes and their impact on Pre-Columbian cultures, en Reindel, M., Wagner, G.A. (eds.), New Technologies for Archaeology. Natural Science in Archaeology: Berlin, Springer, $17-23$.

Fernández-Turiel, J.L., Saavedra, J., PérezTorrado, F.J., Rodríguez-Gonzalez, A., Carracedo, J.G., Osterrieth, M., Carrizo, J.I., Esteban, G., 2013, The largest Holocene eruption of the Central Andes found (resumen), en AGU Fall Meeting, San Francisco, USA, CD.

Goudie, A. (ed.), 2004, Encyclopedia of geomorphology: London, Routledge Press, $2333 \mathrm{p}$.

Günster, N., Skowronek, A., 2001, Sediment-soil sequences in the Granada Basin as evidence for long-and short-term climatic changes during the Pliocene and Quaternary in the Western Mediterranean: Quaternary International, 78(1), 17-32.

Harvey, A.M., 1997, The role of alluvial fans in arid zone fluvial systems, en Thomas, D.S.G. 
(ed.), Arid zone geomorphology: Processes, form and change in drylands: United Kingdom, Wiley-Blackwell, 231-259.

Harvey, A.M., 2002, Effective timescales of coupling within fluvial systems: Geomorphology, 44(3), 175-201.

Harvey, A.M., Mather, A.E., Stokes, M., 2005, Alluvial fans: geomorphology, sedimentology, dynamics - introduction. A review of alluvial-fan research: Geological Society, London, Special Publications, 251(1), 1-7.

Homburg, J.A., Sandor, J.A., 2011, Anthropogenic effects on soil quality of ancient agricultural systems of the American Southwest: Catena, 85(2), 144-154.

Hooke, R.L., 2000, On the history of humans as geomorphic agents: Geology, 28(9), 843-846.

Huckleberry, G., Duff, A.I., 2008, Alluvial cycles, climate, and pueblo an settlement shifts near Zuni Salt Lake, New Mexico, USA: Geoarchaeology, 23(1), 107-130.

Janusek,J.W., 2004, Collapse as cultural revolution: Power and identity in the Tiwanaku to Pacajes transition: Archeological Papers of the American Anthropological Association, 14(1), 175-209.

Lesschen, J.P., Cammeraat, L.H., Kooijman, A.M., van Wesemael, B., 2008, Development of spatial heterogeneity in vegetation and soil properties after land abandonment in a semi-arid ecosystem: Journal of Arid Environments, 72(11), 2082-2092.

Maestre, F.T., Quero, J.L., Gotelli, N.J., Escudero, A., Ochoa, V., Delgado-Baquerizo, M., García-Gómez, M., Bowker, M.A., Soliveres, S., Escolar, C., García-Palacios, P., Berdugo, M., Valencia, E., Gozalo, B., Gallardo, A., Aguilera, L., Arredondo, T., Blones, J., Boeken, B., Bran, D., Conceição, A.A., Cabrera, O., Chaieb, M., Derak, M., Eldridge, D.J., Espinosa, G.I., Florentino, A., Gaitán, J., Gatica, M.G., Ghiloufi, W., GómezGonzález, S., Gutiérrez, J.R., Hernández,
R.M., Huang, X., Huber-Sannwald, E., Jankju, M., Miriti, M., Monerris, J., Mau, R.L., Morici, E., Naseri, K., Ospina, A., Polo, V., Prina, A., Pucheta, E., RamírezCollantes, D.A., Romão, R., Tighe, M., Torres-Díaz, C., Val, J., Veiga, J.P., Wang, D., Zaady, E., 2012, Plant species richness and ecosystem multifunctionality in global drylands: Science, 335(6065), 214-218.

May, S. M., Zander, A., Francois, J. P., Kelletat, D., Pötsch, S., Rixhon, G., Brückner, H., 2015, Chronological and geoarchaeological investigations on an anthropogenic shell accumulation layer in the Longotoma dune field (Central Chile): Quaternary International, 367, 32-41.

Peña Monné, J.L., 1996, Los valles holocenos del escarpe de yesos de Juslibol (sector central de la Depresión del Ebro). Aspectos geomorfológicos y geoarqueológicos: Arqueología Espacial, 15, 83-102.

Peña Monné, J.L., 2018, Geoarqueología aplicada a la reconstrucción paleoambiental: la evolución del Holoceno superior en el NE de España, en Jordá, J., Borja, F. (Eds.): Boletín Geológico y Minero, 129, 285-303.

Peña Monné, J.L., González, J.R., 1992, Hipótesis evolutiva de los cambios en la dinámica geomorfológica del Baix Cinca y Segre (Depresión del Ebro) durante el Pleistoceno superior-Holoceno a partir de los datos geoarqueológicos: Cuaternario y Geomorfología, 6, 103-110.

Peña Monné, J.L., Longares, L.A., 2015, Estudio alterológico de los abrigos con pinturas rupestres de Tormón y Bezas (Sierra de Albarracín), en Bea, M., Angás, J. (coords.), Las pinturas rupestres de Bezas y Tormón (Teruel): Zaragoza, España, Parque Cultural de Albarracín y Dirección General de Bellas Artes, 138-155.

Peña-Monné, J.L., Sampietro-Vattuone, M.M., 2014, Geoarchaeological and 
paleoenvironmental reconstructions through evolutionary models: dryland applications: European Geologist Magazine, 38, 40-44.

Peña-Monné, J.L., Sampietro-Vattuone, M.M., 2016, Geomorphology of the alluvial fans in Colalao del Valle-Quilmes area (Santa María Valley, Tucumán Province, Argentina): Journal of Maps, 12, 460-465.

Peña Monné, J.L., Sampietro Vattuone, M.M., 2016, La secuencia paleoambiental holocena de la vertiente oriental de Loma Pelada (Valle de Tafi, Noroeste Argentino): cambios climáticos y acción humana), en Sampietro Vattuone, M.M., Peña Monné, J.L. (eds.), Geoarqueología de los Valles Calchaquíes: Tucumán, Argentina, Laboratorio de Geoarqueología, 23-64.

Peña Monné, J.L., Sancho, C., 2003, Mecanismos de alteración de la roca y su implicación en el deterioro de grabados rupestres y otros restos arqueológicos, en González, J.R. (coord.), Actes del I Congrés Internacional de gravats rupestres i murals. Homenatge a Lluis DiezCoronel 1992, Lleida, 207-230.

Peña Monné, J.L., Chueca, J., Julián, A., Echeverría, M.T., 1996, Reconstrucciones paleoambientales en el sector central de la Depresión del Ebro a partir de rellenos de valle y conos aluviales, en Pérez Alberti, A. (ed.), Dinámica y evolución de medios cuaternarios, Xunta de Galicia, Santiago, 291-307.

Peña Monné, J.L., Julián, A., Chueca, J., Echeverría, M.T., Ángeles, G., 2004, Etapas de evolución holocena en el valle del río Huerva: Geomorfología y Geoarqueología, en Peña Monné, J.L., Longares, L.A., SánchezFabre, M. (eds.), Geografía Física de Aragón. Aspectos generales y temáticos: Zaragoza, Universidad de Zaragoza e Institución Fernando el Católico, 289-302.

Peña Monné, J.L., Rubio, V., González, J.R., 2005, Aplicación de modelos geomorfológicos evolutivos al estudio de yacimientos arqueológicos en medios semiáridos (Depresión del Ebro, España) (trabajo completo), en X Coloquio Ibérico de Geografía. A Geografia ibérica no cotexto europeo: Évora, Universidad de Évora, 15 p. Peña-Monné, J.L., Sancho, C., SampietroVattuone, M.M., Rivelli, F., Rhodes, E.J., Osácar-Soriano, M.C., Rubio-Fernández, V., García-Giménez, R., 2015, Environmental change over the last millennium recorded in the Cafayate dune field (NW Argentina): Palaeogeography, Palaeoclimatology, Palaeoecology, 438, 352-363.

Peña-Monné, J.L., Sampietro-Vattuone, M.M., Longares-Aladrén, L.A., Pérez-Lambán, F., Sánchez-Fabre, M., Alcolea-Gracia, M., Vallés, L., Echeverría-Arnedo, M.T., Baraza, C., 2018, Holocene alluvial sequence of Val de Zaragoza (Los Monegros) in the palaeoenvironmental context of the Ebro Basin (Spain): Cuadernos de Investigación Geográfica, 44(1), 321-348.

Pérez-Lambán, F., Peña-Monné, J.L., FanloLoras, J., Picazo-Millán, J. V., Badia-Villas, D., Rubio-Fernández, V., García-Giménez, R., Sampietro-Vattuone, M.M., 2014, Paleoenvironments and Geoarchaeological Reconstruction from Late Holocene Slope Records (Lower Huerva Valley, Ebro Basin, NE Spain): Quaternary Research, 81(1), $1-14$.

Porta Casanellas, J., Reguerín, L.A., de Laburu, M.R., 2003, Edafología para la agricultura y el medio ambiente. Mundiprensa, España. Retallack, G.J., 2008, Rocks, views, soils and plants at the temples of ancient Greece: Antiquity, 82(317), 640-657.

Sampietro-Vattuone, M.M., Peña-Monné, J.L., 2016, Geomorphological dynamic changes during the Holocene through ephemeral stream analyses from Northwest Argentina: Catena, 147, 663-677.

Sampietro Vattuone, M.M., Peña Monné, J.L., Maldonado, M.G., Sancho Marcén, C., Báez, W., Sola, A., Blasi, A., 2018, Cambios ambientales durante el Holoceno 
superior registrados en secuencias morfosedimentarias fluvio-eólicas del valle de Santa María (Noroeste Argentino): España, Boletín Geológico y Minero, 129(4), 647-669.

Sampietro-Vattuone, M.M., Peña-Monné, J.L., Roldán, J., Maldonado, M.G., 2014, Reconstruction of agrarian practice and land impact in the drylands: A geoarchaeological approach: European Geologist Magazine, 38, 5-8.

Sampietro Vattuone, M.M., Sola, A., Báez, W., Peña Monné, J.L., 2017, Aplicación de la correlación geoquímica de niveles cineríticos en la reconstrucción de las secuencias morfosedimentarias holocenas del valle de Tafí, en XX Congreso Geológico Argentino: Tucumán, Argentina, 67-72.

Sancho, C., Gutiérrez, M., Peña, J.L., Burillo, F., 1988, A quantitative approach to scarp retreat starting from triangular slope facets (Central Ebro Basin, Spain), en Harvey, A.M., Sala, M. (eds.), Geomorphic processes In Environments With Strong Seasonal Contrasts. II: Geomorphic Systems: Catena Suppl. 13, 139-146.
Schiffer, M.B., 1990. Contexto arqueológico y contexto sistémico: Boletín de Antropología Americana, 22, 81-93.

Schumm, S.A., 1979, Geomorphic thresholds: the concept and its applications: Transactions of the Institute of British Geographers, 485-515.

Small, R.J., Clark, M.J., 1982, Slopes and weathering: New York, U.S.A., Cambridge University Press.

Vita-Finzi, C., 1969, The Mediterranean valleys. Geological changes in historical times: Cambridge, London, Cambridge University Press.

Waters, M.R., 2000, Alluvial stratigraphy and geoarchaeology in the American Southwest: Geoarchaeology, 15(6), 537-557.

Williams, P.R., 2002, Rethinking disaster-induced collapse in the demise of the Andean highland states: Wari and Tiwanaku: World Archaeology, 33(3), 361-374.

Zori, C., Brant, E., 2012, Managing the risk of climatic variability in late prehistoric northern Chile: Journal of Anthropological Archaeology, 31, 403-421. 